\title{
The AIFELL Score as a Predictor of Coronavirus Disease 2019 (COVID-19) Severity and Progression in Hospitalized Patients
}

\author{
Ian Levenfus ${ }^{1,2, *(1)}$, Enrico Ullmann ${ }^{3,4,5}{ }^{(0}$, Katja Petrowski ${ }^{6}$, Jutta Rose ${ }^{7}$, Lars C. Huber ${ }^{7}$, \\ Melina Stüssi-Helbling ${ }^{7,+}$ and Macé M. Schuurmans ${ }^{1,2,+}+$ (i)
}

1 Department of Pulmonology, University Hospital Zurich, 8091 Zurich, Switzerland; mace.schuurmans@usz.ch

2 Faculty of Medicine, University of Zurich, 8032 Zurich, Switzerland

3 Department of Medicine, Technical University Dresden, 01307 Dresden, Germany; enrico.ullmann@uniklinikum-dresden.de

4 Department of Pediatric Psychiatry, Psychotherapy and Psychosomatics, University of Leipzig Medical Center, 04103 Leipzig, Germany

5 Department of Medical Biology, South Ural State University, 454080 Chelyabinsk, Russia

6 Medical Psychology and Sociology, Johannes Gutenberg University Mainz, 55131 Mainz, Germany; kpetrows@uni-mainz.de

7 Clinic for Internal Medicine, Department of Internal Medicine, City Hospital Zurich Triemli, 8063 Zurich, Switzerland; jutta.rose@triemli.zuerich.ch (J.R.); lars.huber@zuerich.ch (L.C.H.); melina.stuessi-helbling@triemli.zuerich.ch (M.S.-H.)

* Correspondence: info@levenfus.com or jan.levenfus@usz.ch

+ These authors contributed equally to this work.

check for updates

Citation: Levenfus, I.; Ullmann, E.; Petrowski, K.; Rose, J.; Huber, L.C.; Stüssi-Helbling, M.; Schuurmans, M.M. The AIFELL Score as a Predictor of Coronavirus Disease 2019 (COVID-19) Severity and Progression in Hospitalized Patients. Diagnostics 2022, 12, 604. https:// doi.org/10.3390/diagnostics12030604

Academic Editor: Anna Baraniak

Received: 31 January 2022

Accepted: 23 February 2022

Published: 27 February 2022

Publisher's Note: MDPI stays neutral with regard to jurisdictional claims in published maps and institutional affiliations.

Copyright: (C) 2022 by the authors. Licensee MDPI, Basel, Switzerland. This article is an open access article distributed under the terms and conditions of the Creative Commons Attribution (CC BY) license (https:// creativecommons.org/licenses/by/ $4.0 /)$.

\begin{abstract}
Since the beginning of the COVID-19 pandemic, SARS-CoV-2 has caused a global burden for health care systems due to high morbidity and mortality rates, leading to caseloads that episodically surpass hospital resources. Due to different disease manifestations, the triage of patients at high risk for a poor outcome continues to be a major challenge for clinicians. The AIFELL score was developed as a simple decision instrument for emergency rooms to distinguish COVID-19 patients in severe disease stages from less severe COVID-19 and non-COVID-19 cases. In the present study, we aimed to evaluate the AIFELL score as a prediction tool for clinical deterioration and disease severity in hospitalized COVID-19 patients. During the second wave of the COVID-19 pandemic in Switzerland, we analyzed consecutively hospitalized patients at the Triemli Hospital Zurich from the end of November 2020 until mid-February 2021. Statistical analyses were performed for group comparisons and to evaluate significance. AIFELL scores of patients developing severe COVID-19 stages IIb and III during hospitalization were significantly higher upon admission compared to those patients not surpassing stages I and IIa. Group comparisons indicated significantly different AIFELL scores between each stage. In conclusion, the AIFELL score at admission was useful to predict the disease severity and progression in hospitalized COVID-19 patients.
\end{abstract}

Keywords: COVID-19; SARS-CoV-2; score; prediction; severe disease

\section{Introduction}

Two years after coronavirus disease 2019 (COVID-19) became a worldwide pandemic, the causative agent named severe acute respiratory syndrome coronavirus 2 (SARS-CoV-2) is still a considerable burden for the health care systems of many countries, leading to restrictions of personal movement and business, as well as travel, and sometimes even leading to lockdowns. Despite available vaccines and associated government-funded vaccination campaigns, the spread of SARS-CoV-2 has not been stopped yet and has resulted in recurrent waves of increasing infection rates, which have put a considerable strain on hospitals and, in particular, their intensive care units (ICU). Different mutations of the SARS-CoV-2 spike protein occurred, leading to the emergence of new strains, including the Alpha, Beta, Gamma, Delta and Omicron variants [1,2], which were declared to be 
variants of concern (VOC) by the World Health Organization (WHO), as they are suspected to cause increased virulence $[1,3]$, higher hospitalization or mortality rates $[4,5]$ or an immune evasion [6,7].

Vaccination campaigns, though initially successful in countries such as Israel [8] or Great Britain [9], have been jeopardized by an incomplete effectiveness of the available vaccines and associated vaccine breakthroughs $[7,10]$, decreasing neutralizing antibody titers over time [11] and vaccine hesitancy in certain parts of the population [12], as well as the limited availability of vaccines in poor countries [13]. For this reason, and due to a rapid spread of the Delta and, later, the Omicron VOC, vaccination campaigns partly suffered setbacks, resulting in further waves of increased infection and hospital occupancy rates [14].

Currently, the main concern is severe cases causing the need for intensive care treatment. Although different testing approaches with sufficient capabilities, including quantitative polymerase chain reaction (qPCR) and rapid antigen tests, are currently widely available in industrialized countries, it is still a challenge to identify patients at high risk for deterioration or severe disease course in emergency rooms, hospital wards or general practice offices in order to give them the necessary attention. Clinical presentations of COVID-19, especially among outpatients, can vary greatly [15] and, identifying and monitoring patients with a high probability of clinical deterioration is crucial for making targeted therapeutic decisions as early as possible.

The AIFELL score was developed and used as a simple frontline triage tool for patients with suspected COVID-19 during the first wave of the pandemic to identify symptomatic patients infected with SARS-CoV-2 from patients presenting with unspecific general or respiratory symptoms in the ER or general practice setting. It includes the patient history components of altered smell or taste and fever, radiologically documented lung infiltrates and the laboratory parameters of C-reactive protein (CRP), elevated lactate dehydrogenase (LDH) and lymphocytopenia (absolute count) [16].

During subsequent increases in infection rates after the first wave, other clinical applications of the simple score were taken into consideration. Since patients in more severe COVID-19 stages II and III (Figure 1) could be identified at hospital admission by the use of this score, the predictive capability of the AIFELL score regarding disease deterioration until hospital discharge was therefore evaluated in hospitalized patients to assess its overall performance as a prediction instrument for COVID-19 progression.

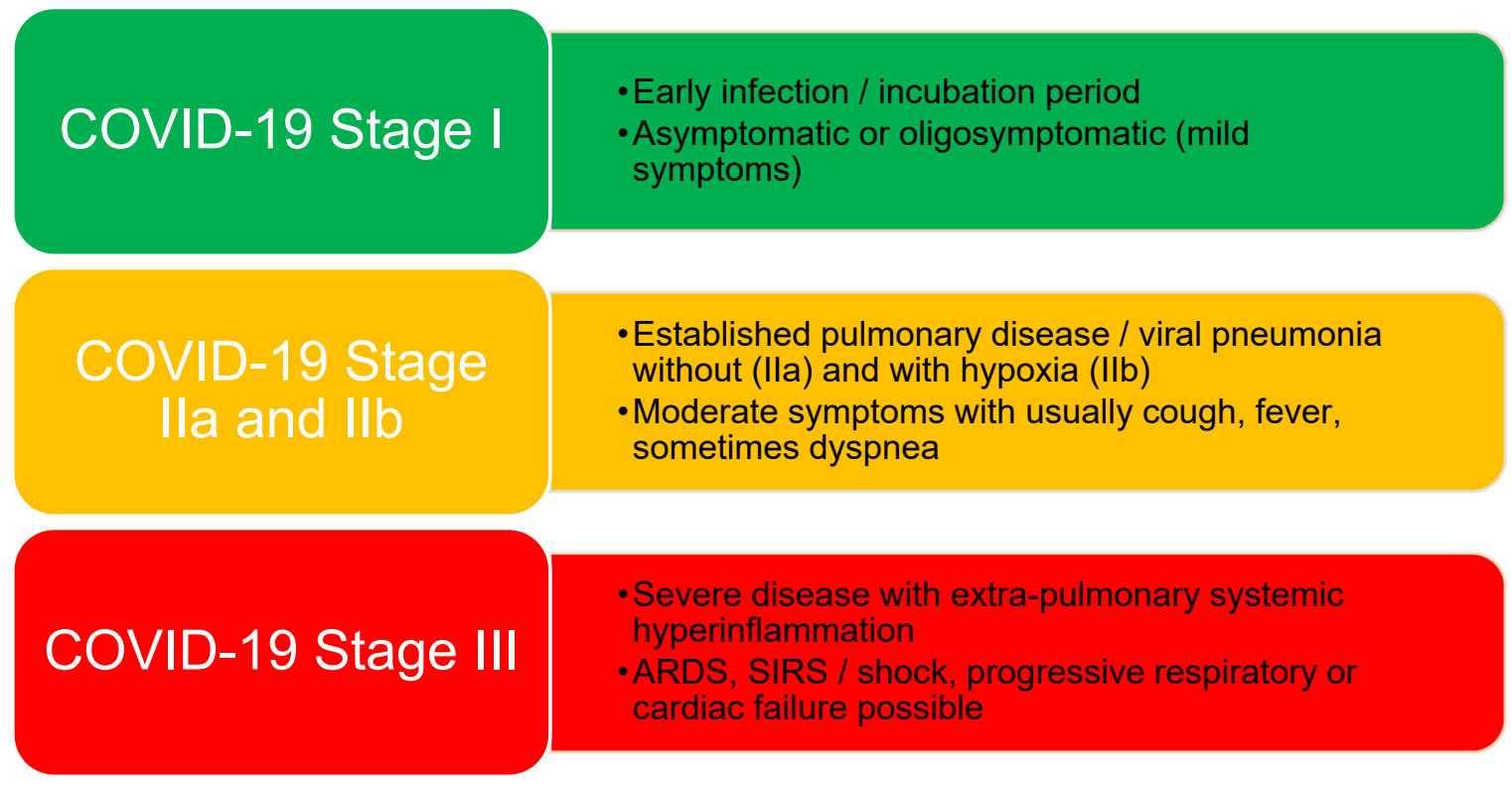

Figure 1. COVID-19 stages as suggested by Siddiqi and Mehra with brief descriptions of their criteria. 


\section{Materials and Methods}

\subsection{Design}

The score was retrospectively applied to consecutively hospitalized SARS-CoV-2positive patients from 22 November 2020 until 17 February 2021 that were treated at the City Hospital Zurich Triemli (Stadtspital Zürich Triemli) during the second wave of the COVID-19 pandemic in Switzerland. The Department of Internal Medicine of the Triemli Hospital agreed to participate as an external partner to apply the AIFELL score in a different hospital location than where it was initially developed. Patients were either admitted through the emergency rooms (ER) from an outpatient setting or directly to the medical ward or the ICU from other hospitals in the area around Zurich (Switzerland). SARS-CoV-2 swabs for qPCR analyses were either performed in the ER of the Triemli Hospital or by the hospitals and outpatient clinics who referred the patients for further treatment. Inclusion criteria were a positive SARS-CoV-2 swab result analyzed using qPCR at admission, a blood sample available upon admission, including at least two of the three considered laboratory parameters (CRP, LDH and total lymphocyte count), chest imaging (X-ray or computed tomography of the thorax) and documented body temperature. Declaration of consent for the use of health-related data and samples for research purposes was signed by every patient. Exclusion criteria were patients with fewer than two laboratory parameters available and missing chest imaging or documentation of body temperature. In addition, patients were excluded if COVID-19 was not the main reason for hospitalization in order to prevent bias regarding laboratory values. AIFELL scores were calculated for each patient at hospital admission, as described in our previous publication [16]. Due to varying reference ranges for LDH between different hospitals, the original protocol was slightly modified and the LDH limit was defined as the 85th percentile of the maximum value of the LDH reference range, as originally observed in the pilot population at the University Hospital Zurich. Non-measurable LDH results due to hemolysis were also considered to be elevated, which is in line with the fact that hemolysis has been reported to be associated with COVID-19 $[17,18]$. Since patients with fever often take antipyretic medications before seeing a physician or presenting at the emergency room, attention was paid to history of fever during the last 3 days before hospital admission, and the highest value measured was taken into account. COVID-19 stages according to Siddiqi and Mehra [19] were assigned based on medical records at hospital admission and in the course, especially at disease deterioration. This classification was chosen because the authors suggested specific therapeutic approaches for each stage [19]. Important criteria defining disease stages are described in Figure 1. The initial and the maximum stage during hospitalization were documented to evaluate disease progression. The study was approved by the Institutional Review Board of the Canton of Zurich (Cantonal Ethics Committee, $\mathrm{Nr}$. 2020-03036).

\subsection{Statistical Analysis}

For baseline characteristics, a test for normal distribution and outliers, as well as a zstandardization, were performed on the original raw data. Student's $t$-test, a multiple linear regression analysis and an ANOVA with multiple measurements were calculated for group comparisons and to determine statistical significance. A multiple linear regression was performed with the AIFELL score at hospital admission to evaluate its predictive capability regarding the maximum COVID-19 stage developed during hospitalization. Next, the course of the illness was analyzed by a two-factorial ANOVA for repeated measurements with within-factor time (pre- and post-measurement) and between-factor group (AIFELL score). In order to account for the influence of sphericity, a Greenhouse-Geisser/Bonferroni correction for repeated testing was implemented. For data collection and statistical analyses, Microsoft Excel 2016 and SPSS 24 were used. Results are given as mean values \pm standard deviation (SD) unless indicated otherwise. 


\section{Results}

The mean age of the included consecutively hospitalized COVID-19 patients $(n=154$, $64 \%$ male) was 69 years \pm 15.7 (range from 23 to 95 years). Baseline demographic, clinical and laboratory characteristics are shown in Table 1.

Table 1. Baseline characteristics, including COVID-19 stages, AIFELL scores and clinical and laboratory values $(n=154)$.

\begin{tabular}{|c|c|c|}
\hline Baseline Characteristics & Mean (Range)/Total Number (Percentage) & SD \\
\hline \multicolumn{3}{|l|}{ Demographics } \\
\hline Age (years) & $69(23-95)$ & 15.7 \\
\hline Sex (male) & $99(64.2 \%)$ & \\
\hline \multicolumn{3}{|l|}{ Clinical } \\
\hline Temperature $\left({ }^{\circ} \mathrm{C}\right)$ & $38(35.6-40)$ & 0.92 \\
\hline $\mathrm{SpO} 2(\%)$ & $92.3(60-100)$ & 6.75 \\
\hline Heart rate (bpm) & $85.7(57-130)$ & 15.6 \\
\hline \multicolumn{3}{|l|}{ Blood pressure $(\mathrm{mmHg})$} \\
\hline Systolic & $135.5(72-236)$ & 23.5 \\
\hline Diastolic & $73.7(40-110)$ & 13.8 \\
\hline Respiratory rate (cycles/Min) & $23.6(8-40)$ & 6.3 \\
\hline Altered smell or taste noted & $16(10.4 \%)$ & \\
\hline Infiltrates documented & $142(92.2 \%)$ & \\
\hline \multicolumn{3}{|l|}{ Laboratory } \\
\hline $\mathrm{CRP}(\mathrm{mg} / \mathrm{L})$ & $97(0.6-422)$ & 79.5 \\
\hline $\mathrm{LDH}(\mathrm{U} / \mathrm{L})$ & $382(176-1166)$ & 176 \\
\hline Lymphocyte count $\left(10^{9}\right.$ cells/L) & $1.0(0.1-2.7)$ & 0.465 \\
\hline \multicolumn{3}{|l|}{ Medications administered } \\
\hline Antibiotics & $70(45.6 \%)$ & \\
\hline Dexamethason & $83(53.9 \%)$ & \\
\hline Remdesivir & $76(49.4 \%)$ & \\
\hline \multicolumn{3}{|l|}{ Outcomes } \\
\hline Ventilation (NIV, intubation) & $30(19.5 \%)$ & \\
\hline Exitus & $14(9.1 \%)$ & \\
\hline \multicolumn{3}{|l|}{$\begin{array}{l}\text { COVID-19 severity stages } \\
\text { at admission } \\
\text { according to Siddiqi \& Mehra }\end{array}$} \\
\hline Stage I & $13(8.4 \%)$ & \\
\hline Stage IIa & $35(22.7 \%)$ & \\
\hline Stage IIb & $80(52 \%)$ & \\
\hline Stage III & $26(16.9 \%)$ & \\
\hline \multicolumn{3}{|c|}{$\begin{array}{l}\text { Maximum COVID-19 severity stage during } \\
\text { hospitalization }\end{array}$} \\
\hline Stage I & $13(8.4 \%)$ & \\
\hline Stage IIa & $16(10.4 \%)$ & \\
\hline Stage IIb & $87(56.5 \%)$ & \\
\hline Stage III & $38(24.7 \%)$ & \\
\hline
\end{tabular}


Table 1. Cont.

\begin{tabular}{cc}
\hline Baseline Characteristics & Mean (Range)/Total Number (Percentage) \\
\hline AIFELL scores at admission & \\
\hline 0 & $1(0.66 \%)$ \\
1 & $1(0.66 \%)$ \\
2 & $11(7.1 \%)$ \\
3 & $43(27.9 \%)$ \\
4 & $66(42.9 \%)$ \\
5 & $31(20.1 \%)$ \\
6 & $1(0.66 \%)$ \\
\hline
\end{tabular}

$\mathrm{NIV}$, non-invasive ventilation; bpm, beats per minute; CRP, C-reactive protein; $\mathrm{LDH}$, lactate dehydrogenase.

The average AIFELL score at hospital admission, regardless of the disease stage, was $3.7 \pm 0.96$. A stage-based comparison of AIFELL scores revealed significant differences between each stage (Table 2). A group comparison of the distribution of AIFELL scores in different disease stages with two-tailed $t$-tests showed highly significant results $(p<0.01)$.

Table 2. Distribution of the AIFELL scores according to COVID-19 stages.

\begin{tabular}{|c|c|c|c|c|}
\hline $\begin{array}{c}\text { Maximum COVID-19 Stage during } \\
\text { Hospitalization }\end{array}$ & $\begin{array}{c}\text { Average AIFELL Score at } \\
\text { Admission }\end{array}$ & SD & $\begin{array}{c}\text { Two-Tailed } \\
t \text {-Test }\end{array}$ & $p$ Value \\
\hline Stage I & 2.08 & 0.86 & Stage I vs. IIa & 0.005 \\
\hline Stage IIa & 3.2 & 0.05 & Stage I vs. II \& III & $<0.0001$ \\
\hline Stage IIb & 3.9 & 0.77 & Stage IIa vs. IIb & 0.002 \\
\hline Stage III & 4.2 & 0.65 & Stage II vs. III & 0.008 \\
\hline TOTAL & 3.73 & 0.96 & & \\
\hline
\end{tabular}

AIFELL scores $\geq 3$ points at admission were associated with development to more severe disease stages (II and III) during the hospital stay, needing a more intensive therapeutic approach (i.e., intermediate or intensive care units). Patients needing oxygen supplementation due to hypoxia during hospitalization (COVID-19 stage IIb and III, $n=125)$ had significantly higher AIFELL scores at admission (3.98 \pm 0.75$)$ compared to patients who maximally developed COVID-19 stages I and IIa $(2.69 \pm 1.11, p<0.0001)$, as shown in Figure 2.

In those patients who deteriorated during hospitalization $(\mathrm{n}=28)$ from stage IIa/Ilb to III or stage IIa to IIb, the average AIFELL score at admission was $3.96 \pm 0.83$. The average AIFELL score of patients who did not deteriorate during hospitalization $(n=126)$ was $3.68 \pm 0.99$, regardless of their disease stage. The mean AIFELL score at admission of patients with mild COVID-19 (stage I), who also did not deteriorate, was $2.08 \pm 0.86$, and is therefore significantly lower than the score obtained of patients reaching severity stages II and III $(p<0.001)$.

\subsection{Linear Regression Analysis}

In order to predict the course of COVID-19 illness during the hospitalization using the AIFELL score at admission, a multiple linear regression was calculated. This multiple linear regression analysis showed that the AIFELL score at hospital admission significantly predicts the progression of the COVID-19 stage during hospitalization $\mathrm{F}(1,152)=21.459$, $p<0.001$ with $R^{2}=35.2 \%$ (Table 3 ). 


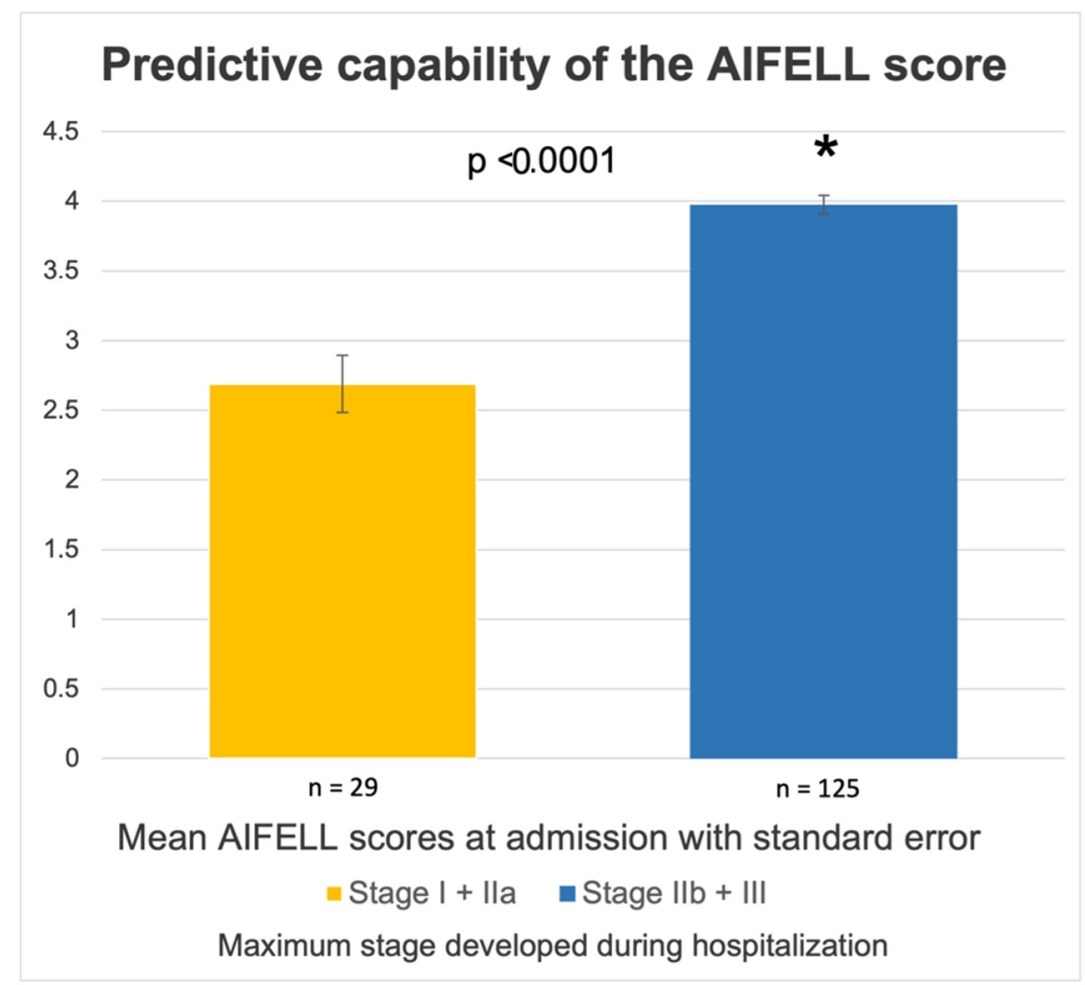

Figure 2. Comparison of mean AIFELL scores at admission between patients who, during the course of the hospitalization, required oxygen supplementation (COVID-19 stage IIb and III) and patients without hypoxia (stage I and IIa). * is a recognized sign for a results being significant.

Table 3. Multiple linear regression of COVID-19 maximal stage during hospitalization by AIFELL score.

\begin{tabular}{cccccc}
\hline & $\boldsymbol{b}$ & $\mathrm{SE}_{\mathbf{B}}$ & $\boldsymbol{\beta}$ & $\boldsymbol{T}$ & $\boldsymbol{p}$ \\
\hline AIFELL score & 0.677 & 0.146 & 0.352 & 4.632 & $0.000^{* * *}$ \\
\hline
\end{tabular}

Note. $\mathbf{R}^{2}=0.352 .{ }^{* * *} p<0.001$.

\subsection{ANOVA with Repeated Measures}

ANOVA with repeated measures with the Greenhouse-Geisser correction showed a significant time effect of symptom development from admission to the worst stage during hospitalization $(\mathrm{F}(1,152)=8.101, p=0.005)$. Furthermore, there was a significant group effect $(F(1,152)=19.867, p \leq 0.001)$, so the AIFELL score predicted different courses of symptom development (i.e., progression to more severe stages) over time during hospitalization (Table 4). Therefore, the COVID-19 stages I, IIa, IIb and III differ significantly in terms of their AIFELL scores.

Table 4. Results of ANOVA with repeated measures comparing AIFELL scores at admission and worst disease stage reached during hospitalization.

\begin{tabular}{|c|c|c|c|c|c|c|}
\hline \multirow[t]{2}{*}{ Parameter } & \multicolumn{2}{|c|}{$\begin{array}{c}\text { ANOVA } \\
\text { Time Effect }\end{array}$} & \multicolumn{2}{|c|}{$\begin{array}{c}\text { ANOVA } \\
\text { Group Effect }\end{array}$} & \multicolumn{2}{|c|}{$\begin{array}{c}\text { ANOVA } \\
\text { Time * Group Interaction }\end{array}$} \\
\hline & $F$ & $P$ & $F$ & $p$ & $F$ & $p$ \\
\hline AIFELL score & 8.101 & $0.005^{* *}$ & 19.867 & $0.000 * * *$ & 1.276 & 0.26 \\
\hline
\end{tabular}

\section{Discussion}

In the presented study, the AIFELL score was used as a prediction instrument for disease severity and progression to evaluate its performance in the hospital setting in 
patients with recently diagnosed COVID-19. Our results indicate that an increased AIFELL score at admission is able to predict the ultimate disease severity or disease progression in patients hospitalized due to COVID-19.

Several scoring systems for COVID-19 with different purposes (triage, prediction) and components have been developed during the pandemic [20-24]. Most of them are considered to be too complex for routine diagnostics since they use advanced formulas for calculation, require extensive prior knowledge regarding medical history and may include a larger number of components or specific laboratory parameters that are not widely or rapidly available in many settings, such as interleukin-2 (IL-2), IL-6, D-dimer, procalcitonin [25] or cluster of differentiation (CD) 4 and CD8 counts, thus limiting their usability in frontline settings or stressful situations. Other scores were developed for specific cohorts (e.g., geriatric patients [26]). Some nonspecific early warning scores have been used in COVID-19 patients in various settings [27-29].

The AIFELL score, in contrast, is a simple tool consisting of only basic, low-cost laboratory parameters, patient history and imaging results. It was initially developed based on data from a mixed, representative cohort of COVID-19 patients and studied in consecutive ER patients with suspected COVID-19. It is easy to calculate and does not necessarily require any additional tools, making it practical for resource-limited settings, such as smaller hospitals or general practitioner offices. Nevertheless, the website www. aifell.net was created to provide a comprehensive overview of all components, and features a basic online calculator, as well as a printable calculation form. Due to specified limits and the objective nature of the components, there is less room for inter-rater variability.

Based on the results of this study, we suggest the calculation of the AIFELL score at hospital admission for every patient with respiratory or other symptoms possibly associated with COVID-19, so it may serve as a triage tool and, in the case of a positive SARSCoV-2 swab, it may additionally serve as a predictor for disease progression. Another reasonable time point for the calculation of the AIFELL score is when disease deterioration has occurred to estimate the probable outcome. Since we demonstrated that the AIFELL score at admission is significantly higher in patients developing more severe COVID-19 stages during hospitalization, it provides useful information for clinical decision making, serving as a red flag for disease deterioration. From a clinical perspective, there is a relevant difference between the COVID-19 stages IIa and IIb, or even III, because hypoxia requires immediate treatment to avoid life-threatening complications. Furthermore, in severe COVID-19, proinflammatory cascades are activated, which eventually may lead to endothelial dysfunction and hypercoagulability, resulting in life-threatening complications, such as myocardial infarction [30] or acute ischemic stroke (AIC), due to inflammationrelated plaque rupture [31]. Therefore, patients in stage IIb need hospital care and patients in stage III are usually transferred to the ICU. The AIFELL score could help in identifying these severe cases, since it predicts the expected disease severity. According to our results, patients with an AIFELL score $\geq 3$ points at admission would need more attention and very likely more resources, whereas patients with lower AIFELL scores may require regular ward care or may be discharged due to the expected better prognosis.

Components of the AIFELL score that are associated with severe stages of COVID-19 in the scientific literature are consolidative infiltrates as a sign of pulmonary involvement [32], fever [33] and elevated CRP levels [25,34] as a result of a systemic inflammatory process. Further components associated with severe stages of COVID-19 are elevated levels of $\mathrm{LDH}$, which indicate pronounced tissue damage [35,36] and a lower lymphocyte count [37], possibly due to a chemotaxis of lymphocytes to lymphoid organs or a direct infection and destruction of angiotensin-converting enzyme 2 (ACE2) positive lymphocytes [36].

Dysosmia and dysgeusia tend to be associated with a mild or moderate disease course [38], but play an important role in the triage process for which the AIFELL score was initially generated.

Other inflammation biomarkers, such as the neutrophil count, the neutrophil-tolymphocyte ratio (NLR) and monocyte-to-lymphocyte ratio (MLR), as well as the platelet 
count and lymphocyte-to-platelet ratio (LPR), which are usually available or can be calculated after a differential blood count has been performed, could be used to expand or complement the AIFELL score. The importance of detailed analyses of these simple blood parameters has already been highlighted previously [39]. Furthermore, the systemic immune inflammation (SII) index, which is also easily calculated based on lymphocyte, neutrophil and platelet counts and reflects the innate, as well as the adaptive, immune response in COVID-19 and in some other diseases, may potentially add value to the AIFELL score. In particular, the serial calculation of the SII based on repeated laboratory samples of the differential blood count (serial systemic immune inflammation indices, SSIIi) seems to be important, as SSIIi peaks were shown to be associated with neurological or thromboembolic complications [40]. Therefore, SSI and SSIIi may be calculated additionally to complement the information of the AIFELL score.

Biomarkers, such as interleukin-(IL)-1, IL-6, cardiac troponin I, d-dimers, ferritin or procalcitonin, were originally not included as components of the AIFELL score since they are not measured routinely, are usually more expensive and are generally not easily available.

Our study has several limitations: During the second wave, hospitalized patients tended to be more severely ill compared to the first wave. Therefore, less severe COVID-19 stages (I and IIa) are underrepresented in our cohort. It was unknown which strains of SARS-CoV-2 were causing the infection at the time of the study, since sequencing was not routinely performed during the second wave. Other limitations of the study are its retrospective nature and the single-center setting. Due to the retrospective nature of the study, not all data sets were complete. Information about altered smell or taste was missing in many cases, since it was not routinely asked when medical history was obtained. Missing information was rated as negative for the respective component of the score. This may have led to lower average AIFELL scores and explains the low number of patients with the highest AIFELL score of 6 points. Obviously, further research is necessary to validate the AIFELL score as a prediction tool, especially the prospective use of the score in a multicenter setting with a larger cohort of patients. The strengths of the current study are the external application of the score outside of the original hospital setting (University Hospital Zurich) and a mixed cohort of consecutive hospitalized patients during a predefined time frame.

COVID-19 still dominates the medical, social and political discourse, resulting in efforts to develop mechanisms for stopping future waves of the pandemic [41]. During recurring waves with high infection and hospitalization rates, the AIFELL score may continue to be a simple, fast, cost-effective and easily applicable instrument for the triage of outpatients to identify patients prone to developing more severe stages of COVID-19 and to predict their outcome. In particular, low-income countries with fewer resources in their health care systems, and thus a limited availability of advanced laboratory techniques and SARS-CoV-2 testing kits, as well as vaccinations, may benefit from its widespread use [42]. Even in some industrialized countries (e.g., Germany), the rapid spread of the Omicron VOC is pushing PCR testing capabilities to their limits. With large numbers of infected patients, clinical decision instruments to distinguish probable severe cases from rather mild infections are becoming even more important.

Currently available or upcoming IgG1-based monoclonal antibody treatments of COVID-19, such as casirivimab/imdevimab (RegN-Cov2) [43], sotrovimab (Xevudy) [44] or regdanvimab (Regkirona) [45], which can be administered intravenously in an outpatient setting, are intended for patients not yet needing oxygen supplementation but with a high risk of severe disease. As the selection of eligible patients for these therapies may be difficult due to a lack of precise guidelines and disease severity indicators, the AIFELL score could support clinical decision making in these contexts.

In future, after the end of the current COVID-19 pandemic, SARS-CoV-2 may become a relevant respiratory virus of seasonal nature, similar to influenza, with a potential to cause severe complications. Therefore, clinical instruments, such as the AIFELL score, that facilitate triage and enable the prediction of severe stages may remain useful, even after the pandemic situation has largely subsided. 


\section{Conclusions}

The AIFELL score is a simple clinical instrument to predict disease severity or disease progression in patients hospitalized due to COVID-19. This finding supplements its capability to be used as a triage tool in the emergency room setting.

Author Contributions: Conceptualization, I.L. and M.M.S.; methodology, I.L., M.S.-H. and M.M.S.; investigation, I.L., J.R. and M.S.-H.; data curation, I.L. and M.S.-H.; formal analysis, I.L., E.U. and K.P.; validation, M.S.-H. and M.M.S.; writing—original draft preparation, I.L., M.S.-H., K.P. and E.U.; writing-review and editing, M.M.S. and L.C.H.; resources, M.S.-H. and L.C.H.; supervision, M.M.S. and L.C.H.; project administration, M.S.-H. and I.L. All authors have read and agreed to the published version of the manuscript.

Funding: This research received no external funding.

Institutional Review Board Statement: The study was conducted in accordance with the Declaration of Helsinki and approved by the Institutional Review Board of the Canton of Zurich (Cantonal Ethics Committee, Nr. 2020-03036, approved on 26 January 2021).

Informed Consent Statement: Informed consent was obtained from all subjects involved in the study.

Data Availability Statement: Not applicable.

Conflicts of Interest: The authors declare no conflict of interest.

\section{References}

1. Sanches, P.R.S.; Charlie-Silva, I.; Braz, H.L.B.; Bittar, C.; Freitas Calmon, M.; Rahal, P.; Cilli, E.M. Recent Advances in SARS-CoV-2 Spike Protein and RBD Mutations Comparison between New Variants Alpha (B.1.1.7, United Kingdom), Beta (B.1.351, South Africa), Gamma (P.1, Brazil) and Delta (B.1.617.2, India). J. Virus Erad. 2021, 7, 100054. [CrossRef] [PubMed]

2. Thakur, V.; Ratho, R.K. OMICRON (B.1.1.529): A New SARS-CoV-2 Variant of Concern Mounting Worldwide Fear. J. Med. Virol. 2021. [CrossRef] [PubMed]

3. Khateeb, J.; Li, Y.; Zhang, H. Emerging SARS-CoV-2 Variants of Concern and Potential Intervention Approaches. Crit. Care 2021, 25, 244. [CrossRef] [PubMed]

4. Sheikh, A.; McMenamin, J.; Taylor, B.; Robertson, C. SARS-CoV-2 Delta VOC in Scotland: Demographics, Risk of Hospital Admission, and Vaccine Effectiveness. Lancet 2021, 397, 2461-2462. [CrossRef]

5. Challen, R.; Brooks-Pollock, E.; Read, J.M.; Dyson, L.; Tsaneva-Atanasova, K.; Danon, L. Risk of Mortality in Patients Infected with SARS-CoV-2 Variant of Concern 202012/1: Matched Cohort Study. BMJ 2021, 372, n579. [CrossRef]

6. Lazarevic, I.; Pravica, V.; Miljanovic, D.; Cupic, M. Immune Evasion of SARS-CoV-2 Emerging Variants: What Have We Learnt so Far? Viruses 2021, 13, 1192. [CrossRef]

7. Zhang, X.; Wu, S.; Wu, B.; Yang, Q.; Chen, A.; Li, Y.; Zhang, Y.; Pan, T.; Zhang, H.; He, X. SARS-CoV-2 Omicron Strain Exhibits Potent Capabilities for Immune Evasion and Viral Entrance. Signal Transduct. Target. Ther. 2021, 6, 430. [CrossRef]

8. Rosen, B.; Waitzberg, R.; Israeli, A. Israel's Rapid Rollout of Vaccinations for COVID-19. Isr. J. Health Policy Res. 2021, 10, 16. [CrossRef]

9. Lopez Bernal, J.; Andrews, N.; Gower, C.; Robertson, C.; Stowe, J.; Tessier, E.; Simmons, R.; Cottrell, S.; Roberts, R.; O’Doherty, M.; et al. Effectiveness of the Pfizer-BioNTech and Oxford-AstraZeneca Vaccines on COVID-19 Related Symptoms, Hospital Admissions, and Mortality in Older Adults in England: Test Negative Case-Control Study. BMJ 2021, 373, n1088. [CrossRef]

10. Juthani, P.V.; Gupta, A.; Borges, K.A.; Price, C.C.; Lee, A.I.; Won, C.H.; Chun, H.J. Hospitalisation among Vaccine Breakthrough COVID-19 Infections. Lancet Infect. Dis. 2021, 21, 1485-1486. [CrossRef]

11. Naaber, P.; Tserel, L.; Kangro, K.; Sepp, E.; Jürjenson, V.; Adamson, A.; Haljasmägi, L.; Rumm, A.P.; Maruste, R.; Kärner, J.; et al. Dynamics of Antibody Response to BNT162b2 Vaccine after Six Months: A Longitudinal Prospective Study. Lancet Reg. Health Eur. 2021, 10, 100208. [CrossRef]

12. Dror, A.A.; Eisenbach, N.; Taiber, S.; Morozov, N.G.; Mizrachi, M.; Zigron, A.; Srouji, S.; Sela, E. Vaccine Hesitancy: The next Challenge in the Fight against COVID-19. Eur. J. Epidemiol. 2020, 35, 775-779. [CrossRef] [PubMed]

13. Padma, T.V. COVID Vaccines to Reach Poorest Countries in 2023—Despite Recent Pledges. Nature 2021, 595, 342-343. [CrossRef] [PubMed]

14. Wadman, M. A Grim Warning from Israel: Vaccination Blunts, but Does Not Defeat Delta. Science 2021, 373, 838-839. [CrossRef]

15. Cheng, A.; Caruso, D.; McDougall, C. Outpatient Management of COVID-19: Rapid Evidence Review. Am. Fam. Physician 2020, 102, 478-486. [PubMed]

16. Levenfus, I.; Ullmann, E.; Battegay, E.; Schuurmans, M.M. Triage Tool for Suspected COVID-19 Patients in the Emergency Room: AIFELL Score. Braz. J. Infect. Dis. 2020, 24, 458-461. [CrossRef]

17. Sahu, K.K.; Borogovac, A.; Cerny, J. COVID-19 Related Immune Hemolysis and Thrombocytopenia. J. Med. Virol. 2021, 93, 1164-1170. [CrossRef] 
18. Bouchla, A.; Kriebardis, A.G.; Georgatzakou, H.T.; Fortis, S.P.; Thomopoulos, T.P.; Lekkakou, L.; Markakis, K.; Gkotzias, D.; Panagiotou, A.; Papageorgiou, E.G.; et al. Red Blood Cell Abnormalities as the Mirror of SARS-CoV-2 Disease Severity: A Pilot Study. Front. Physiol. 2021, 12, 825055. [CrossRef]

19. Siddiqi, H.K.; Mehra, M.R. COVID-19 Illness in Native and Immunosuppressed States: A Clinical-Therapeutic Staging Proposal. J. Heart Lung Transplant. 2020, 39, 405-407. [CrossRef]

20. Knight, S.R.; Ho, A.; Pius, R.; Buchan, I.; Carson, G.; Drake, T.M.; Dunning, J.; Fairfield, C.J.; Gamble, C.; Green, C.A.; et al. Risk Stratification of Patients Admitted to Hospital with COVID-19 Using the ISARIC WHO Clinical Characterisation Protocol: Development and Validation of the 4C Mortality Score. BMJ 2020, 370, m3339. [CrossRef]

21. Sun, H.; Jain, A.; Leone, M.J.; Alabsi, H.S.; Brenner, L.N.; Ye, E.; Ge, W.; Shao, Y.-P.; Boutros, C.L.; Wang, R.; et al. CoVA: An Acuity Score for Outpatient Screening That Predicts Coronavirus Disease 2019 Prognosis. J. Infect. Dis. 2021, 223, 38-46. [CrossRef] [PubMed]

22. Jehi, L.; Ji, X.; Milinovich, A.; Erzurum, S.; Merlino, A.; Gordon, S.; Young, J.B.; Kattan, M.W. Development and Validation of a Model for Individualized Prediction of Hospitalization Risk in 4536 Patients with COVID-19. PLoS ONE 2020, 15, e0237419. [CrossRef] [PubMed]

23. Chao, H.; Fang, X.; Zhang, J.; Homayounieh, F.; Arru, C.D.; Digumarthy, S.R.; Babaei, R.; Mobin, H.K.; Mohseni, I.; Saba, L.; et al. Integrative Analysis for COVID-19 Patient Outcome Prediction. Med. Image Anal. 2021, 67, 101844. [CrossRef]

24. Soto-Mota, A.; Marfil-Garza, B.A.; Martínez Rodríguez, E.; Barreto Rodríguez, J.O.; López Romo, A.E.; Alberti Minutti, P.; Alejandre Loya, J.V.; Pérez Talavera, F.E.; Ávila Cervera, F.J.; Velazquez Burciaga, A.; et al. The Low-harm Score for Predicting Mortality in Patients Diagnosed with COVID-19: A Multicentric Validation Study. J. Am. Coll. Emerg. Physicians Open 2020, 1, 1436-1443. [CrossRef] [PubMed]

25. Li, T.; Wang, X.; Zhuang, X.; Wang, H.; Li, A.; Huang, L.; Zhang, X.; Xue, Y.; Wei, F.; Ma, C. Baseline Characteristics and Changes of Biomarkers in Disease Course Predict Prognosis of Patients with COVID-19. Intern. Emerg. Med. 2021, 16, 1165-1172. [CrossRef]

26. Pilotto, A.; Azzini, M.; Cella, A.; Cenderello, G.; Castagna, A.; Pilotto, A.; Custureri, R.; Dini, S.; Farinella, S.T.; Ruotolo, G.; et al The Multidimensional Prognostic Index (MPI) for the Prognostic Stratification of Older Inpatients with COVID-19: A Multicenter Prospective Observational Cohort Study. Arch. Gerontol. Geriatr. 2021, 95, 104415. [CrossRef] [PubMed]

27. Su, Y.; Ju, M.; Xie, R.; Yu, S.; Zheng, J.; Ma, G.; Liu, K.; Ma, J.; Yu, K.; Tu, G.; et al. Prognostic Accuracy of Early Warning Scores for Clinical Deterioration in Patients With COVID-19. Front. Med. 2021, 7, 1113. [CrossRef]

28. van Dam, P.M.; Zelis, N.; Stassen, P.; van Twist, D.J.L.; de Leeuw, P.W.; van Kuijk, S.; Buijs, J. Validating the RISE UP Score for Predicting Prognosis in Patients with COVID-19 in the Emergency Department: A Retrospective Study. BMJ Open 2021, 11, e045141. [CrossRef]

29. Pokeerbux, M.R.; Yelnik, C.M.; Faure, E.; Drumez, E.; Bruandet, A.; Labreuche, J.; Assaf, A.; Goffard, A.; Garabedian, C.; Poissy, J.; et al. National Early Warning Score to Predict Intensive Care Unit Transfer and Mortality in COVID-19 in a French Cohort. Int. J. Clin. Pract. 2021, 75, e14121. [CrossRef]

30. Thakkar, S.; Arora, S.; Kumar, A.; Jaswaney, R.; Faisaluddin, M.; Ammad Ud Din, M.; Shariff, M.; Barssoum, K.; Patel, H.P.; Nirav, A.; et al. A Systematic Review of the Cardiovascular Manifestations and Outcomes in the Setting of Coronavirus-19 Disease. Clin. Med. Insights Cardiol. 2020, 14, 117954682097719. [CrossRef]

31. Wijeratne, T.; Gillard Crewther, S.; Sales, C.; Karimi, L. COVID-19 Pathophysiology Predicts That Ischemic Stroke Occurrence Is an Expectation, Not an Exception-A Systematic Review. Front. Neurol. 2021, 11, 1759. [CrossRef]

32. Izcovich, A.; Ragusa, M.A.; Tortosa, F.; Lavena Marzio, M.A.; Agnoletti, C.; Bengolea, A.; Ceirano, A.; Espinosa, F.; Saavedra, E.; Sanguine, V.; et al. Prognostic Factors for Severity and Mortality in Patients Infected with COVID-19: A Systematic Review. PLoS ONE 2020, 15, e0241955. [CrossRef] [PubMed]

33. Tang, M.; Yu, X.-X.; Huang, J.; Gao, J.-L.; Cen, F.-L.; Xiao, Q.; Fu, S.-Z.; Yang, Y.; Xiong, B.; Pan, Y.-J.; et al. Clinical Diagnosis of Severe COVID-19: A Derivation and Validation of a Prediction Rule. World J. Clin. Cases 2021, 9, 2994. [CrossRef] [PubMed]

34. Mosquera-Sulbaran, J.A.; Pedreañez, A.; Carrero, Y.; Callejas, D. C-reactive Protein as an Effector Molecule in Covid-19 Pathogenesis. Rev. Med. Virol. 2021, 31, e2221. [CrossRef] [PubMed]

35. Pan, F.; Yang, L.; Li, Y.; Liang, B.; Li, L.; Ye, T.; Li, L.; Liu, D.; Gui, S.; Hu, Y.; et al. Factors Associated with Death Outcome in Patients with Severe Coronavirus Disease-19 (COVID-19): A Case-Control Study. Int. J. Med. Sci. 2020, 17, 1281. [CrossRef] [PubMed]

36. Khinda, J.; Janjua, N.Z.; Cheng, S.; Heuvel, E.R.; Bhatti, P.; Darvishian, M. Association between Markers of Immune Response at Hospital Admission and COVID-19 Disease Severity and Mortality: A Meta-analysis and Meta-regression. J. Med. Virol. 2021, 93, 1078-1098. [CrossRef]

37. Tjendra, Y.; al Mana, A.F.; Espejo, A.P.; Akgun, Y.; Millan, N.C.; Gomez-Fernandez, C.; Cray, C. Predicting Disease Severity and Outcome in COVID-19 Patients: A Review of Multiple Biomarkers. Arch. Pathol. Lab. Med. 2020, 144, 1465-1474. [CrossRef]

38. Aziz, M.; Goyal, H.; Haghbin, H.; Lee-Smith, W.M.; Gajendran, M.; Perisetti, A. The Association of "Loss of Smell” to COVID-19: A Systematic Review and Meta-Analysis. Am. J. Med. Sci. 2021, 361, 216-225. [CrossRef]

39. Wijeratne, T.; Sales, C.A.; Crewther, S.G.; Nguyen, V.; Karimi, L. First Australian Case of Good Recovery of a COVID-19 Patient With Severe Neurological Symptoms Post Prolonged Hospitalization. Cureus 2020, 12, e10366. [CrossRef]

40. Wijeratne, T.; Wijeratne, C. Clinical Utility of Serial Systemic Immune Inflammation Indices (SSIIi) in the Context of Post COVID-19 Neurological Syndrome (PCNS). J. Neurol. Sci. 2021, 423, 117356. [CrossRef] 
41. Cacciapaglia, G.; Cot, C.; Sannino, F. Multiwave Pandemic Dynamics Explained: How to Tame the next Wave of Infectious Diseases. Sci. Rep. 2021, 11, 6638. [CrossRef] [PubMed]

42. Schultz, M.J.; Gebremariam, T.H.; Park, C.; Pisani, L.; Sivakorn, C.; Taran, S.; Papali, A. Pragmatic Recommendations for the Use of Diagnostic Testing and Prognostic Models in Hospitalized Patients with Severe COVID-19 in Low- and Middle-Income Countries. Am. J. Trop. Med. Hyg. 2021, 104, 34-47. [CrossRef] [PubMed]

43. Weinreich, D.M.; Sivapalasingam, S.; Norton, T.; Ali, S.; Gao, H.; Bhore, R.; Musser, B.J.; Soo, Y.; Rofail, D.; Im, J.; et al. REGNCOV2, a Neutralizing Antibody Cocktail, in Outpatients with COVID-19. N. Engl. J. Med. 2021, 384, 238-251. [CrossRef] [PubMed]

44. Gupta, A.; Gonzalez-Rojas, Y.; Juarez, E.; Crespo Casal, M.; Moya, J.; Falci, D.R.; Sarkis, E.; Solis, J.; Zheng, H.; Scott, N.; et al. Early Treatment for COVID-19 with SARS-CoV-2 Neutralizing Antibody Sotrovimab. N. Engl. J. Med. 2021, 385, 1941-1950. [CrossRef]

45. Lee, J.Y.; Lee, J.Y.; Ko, J.-H.; Hyun, M.; Kim, H.A.; Cho, S.; Lee, Y.D.; Song, J.; Shin, S.; Peck, K.R. Effectiveness of Regdanvimab Treatment in High-Risk COVID-19 Patients to Prevent Progression to Severe Disease. Front. Immunol. 2021, 12, 4998. [CrossRef] 